\title{
Mesoscale modeling of lake effect snow over Lake Erie - sensitivity to convection, microphysics and the water temperature
}

\author{
N. E. Theeuwes, G. J. Steeneveld, F. Krikken, and A. A. M. Holtslag \\ Wageningen University, Meteorology and Air Quality Section, Wageningen, The Netherlands \\ Received: 30 December 2009 - Revised: 3 March 2010 - Accepted: 5 March 2010 - Published: 17 March 2010
}

\begin{abstract}
Lake effect snow is a shallow convection phenomenon during cold air advection over a relatively warm lake. A severe case of lake effect snow over Lake Erie on 24 December 2001 was studied with the MM5 and WRF mesoscale models. This particular case provided over $200 \mathrm{~cm}$ of snow in Buffalo (NY), caused three casualties and $\$ 10$ million of material damage. Hence, the need for a reliable forecast of the lake effect snow phenomenon is evident. MM5 and WRF simulate lake effect snow successfully, although the intensity of the snowbelt is underestimated. It appears that significant differences occur between using a simple and a complex microphysics scheme. In MM5, the use of the simple-ice microphysics scheme results in the triggering of the convection much earlier in time than with the more sophisticated Reisner-Graupel-scheme. Furthermore, we find a large difference in the maximum precipitation between the different nested domains: Reisner-Graupel produces larger differences in precipitation between the domains than "simple ice". In WRF, the sophisticated Thompson microphysics scheme simulates less precipitation than the simple WSM3 scheme. Increased temperature of Lake Erie results in an exponential growth in the 24-h precipitation. Regarding the convection scheme, the updated Kain-Fritsch scheme (especially designed for shallow convection during lake effect snow), gives only slight differences in precipitation between the updated and the original scheme.
\end{abstract}

\section{Introduction}

Forecasting the timing, location and intensity of lake effect snow (LES) is one of the most challenging problems concerning weather forecasting in the Great Lakes region of the U.S.A. and Canada. LES is a mesoscale convective precipitation event that occurs when stably stratified arctic air is destabilized over a relatively warm lake. These storms can result in extreme precipitation with snowfall of $150-250 \mathrm{~cm}$ over a multiday period (Niziol et al., 1995). This has significant impacts on the regional infrastructure and transportation.

Since this type of event cannot be well forecasted using synoptic data (Niziol et al., 1995), a mesoscale meteorological model may provide better results. Ballentine et al. (1998) examined whether a LES storm over Lake Ontario was well represented in a mesoscale model. They managed to forecast the location and intensity of lake effect with MM5 successfully, although there were errors in the timing of a few

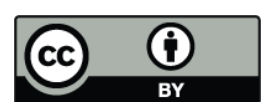

Correspondence to: N. E. Theeuwes

(natalie.theeuwes@wur.nl) hours. They concluded that MM5 was useful for real-time LES forecasts. Other successful studies simulating LES with MM5 include Steenburgh and Onton (2001) and Scott and Sousounis (2001). WRF has not often been used to study LES, except in Maesaka et al. (2006) who found that WRF was able to model LES belts fairly well.

In order to compare MM5 and WRF when simulating LES, both mesoscale models will be used to examine a snow event on 24 and 25 December 2001 in the Buffalo region. LES is driven by convection. We hypothesize that using a different cumulus scheme within the mesoscale models may give a different representation of LES belt. In winter, the amount of snow or rain depends on the model representation of the microphysics and on the temperature difference between the lake and the air. Therefore, the following research questions will be addressed during this descriptive study:

- Will the updated Kain-Fritsch (KF2) cumulus scheme give a better representation of LES over the old version (KF1). 


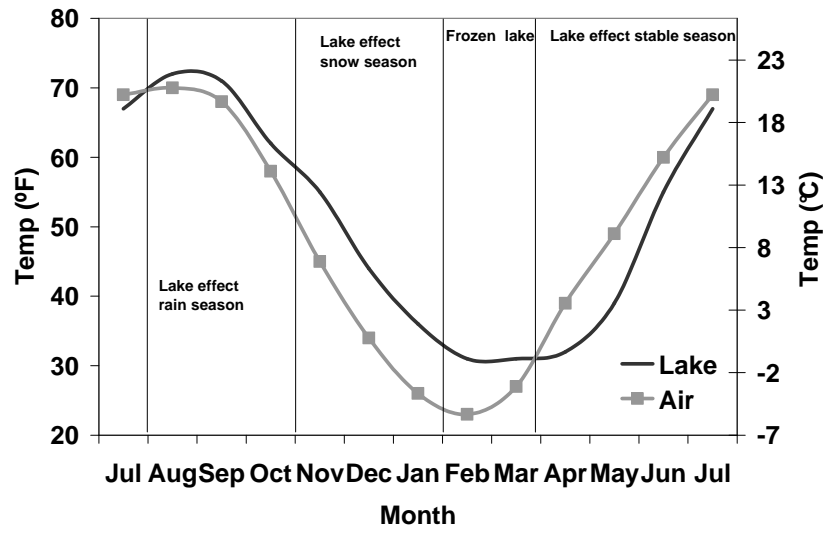

Figure 1. The mean air and Lake Erie temperatures at Buffalo, New York. Reproduced from Niziol et al. (1995).

- How will the precipitation be represented in the mesoscale models with a different explicit moisture scheme (simple and complex)?

- How will the precipitation change with the lake water temperature?

\subsection{Climatology}

The climate in the Great Lakes region is greatly affected by the temperature difference between the air and the lakes. In spring and early summer Lake Erie is colder than the mean air temperature in the Buffalo region (Fig. 1). This initiates relatively cool and humid winds from the lake. During the summer the lake stores a lot of solar energy, which causes a large temperature differences between the lake and the air in fall and early winter, resulting in lake-effect precipitation events. Between August and mid October this precipitation is usually liquid and less intense. Later in the year, arctic air masses cause precipitation to increase and the precipitation type is often snow.

The probability of LES is highest after a low-pressure system has passed over the region, headed east. After such a disturbance, cold air from Canada is brought southward, creating the largest temperature difference between the air and the lake during the winter season, leading to an unstably stratified atmosphere.

The largest amounts of snow accumulate where the prevailing winds blow downwind of the largest fetch over the lake. On the downwind side of Lake Ontario and Lake Erie some regions receive more than $7 \mathrm{~m}$ and $5 \mathrm{~m}$ snow per year respectively. The mean annual snow accumulated in and around Buffalo is about $200 \mathrm{~cm}$. Here the precipitation is also enhanced due to orography, since east of Lake Erie the terrain height increases $\sim 400 \mathrm{~m}$ in $45 \mathrm{~km}$. LES events are persistent, and under favorable conditions they can last for several days over sharply defined regions.

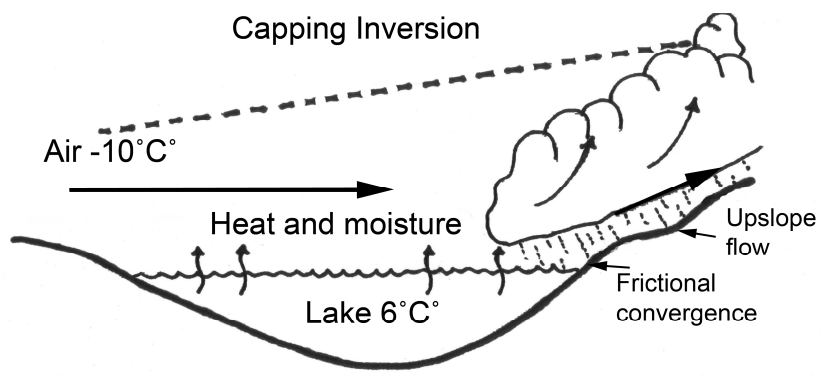

Figure 2. A schematic overview of the important processes driving lake effect snow.

\subsection{Physical processes}

Lake effect snow develops when cold, arctic air travels over a relatively warm lake (Fig. 2). This causes instability and convection. These events occur during what might be categorized as "fair weather" on synoptic scale. Typically, a LES event occurs several hours after the passage of a cold front (Lavoie, 1972).

Lavoie (1972) concluded that the most important factor in forcing lake effect convection is the temperature difference between the lake and the air. Wilson (1977) found that during the late fall and winter Lake Ontario generally stimulates precipitation when the temperature at $850 \mathrm{hPa}$ is $7^{\circ} \mathrm{C}$ lower than the temperature of the lake, while Holroyd (1971) observed that a temperature difference of at least $13{ }^{\circ} \mathrm{C}$ is needed for pure LES (dry adiabatic). This temperature difference results in absolute instability and vertical transport of heat and moisture.

Often arctic air masses are accompanied by a strong inversion, which determines the convective cloud growth. Holroyd (1971) also found that differences in surface roughness between the water and landmass create frictional convergence, and well-organized vertical motion, which raises the height of the capping inversion and enhances convection.

The location and orientation of the snow bands is determined by the winds between the surface and the height of the capping inversion. In most cases, the snowbelt is aligned in the direction of the steering wind. Throughout the atmospheric boundary layer (ABL) directional shear should be limited $\left(<30^{\circ}\right)$ (Niziol, 1987), because convective cells tend to be less organized or fall apart with too much directional shear.

\section{Case selection and available data}

This paper reports on the LES event that occurred on 24 December 2001 and lasted until the morning of 25 December 2001. During this episode, a low-pressure system with a cold front had passed through the region. The flow over Lake Erie was westerly to northwesterly and it lasted for several days bringing cold arctic air from Canada, resulting in LES 


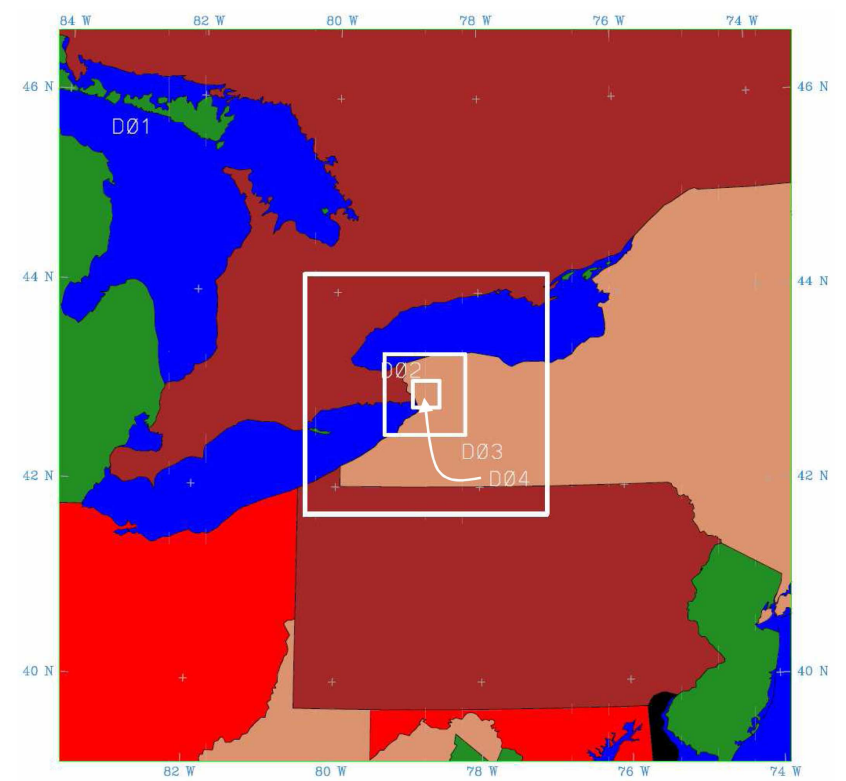

Figure 3. Four nested model domains in MM5 and WRF, centered at Buffalo.

over Lake Erie and Lake Ontario. Buffalo received over $2 \mathrm{~m}$ of snow over five consecutive days, which is the same as the climatological mean accumulated snow in the Buffalo region over the entire cold season.

\section{Methodology}

To simulate LES two mesoscale numerical models were used, namely the National Center for Atmospheric Research/Penn State Mesoscale Model Version 5 (MM5) (Grell et al., 1994) and the Advanced Research WRF Version 3.0 (ARW) (Skamarock et al., 2008). We defined four two-way nested domains, with a resolution of $27,9,3$, and $1 \mathrm{~km}$ respectively (Fig. 3). Each nest had 31 by 31 gridpoints and was centered around Buffalo. The models used 27 sigma/eta levels, of which 23 were below $700 \mathrm{hPa}$. The initial conditions originate from the European Centre for Medium-Range Weather Forecasts (ECMWF) operational analysis fields.

The ABL scheme used for this research is the computationally efficient Medium Range Forecast (MRF) model (Hong and Pan, 1996), since it has shown superior skill over other ABL schemes for convective conditions (e.g. Holtslag and Boville, 1993). The radiation scheme used was the cloud radiation. Table 1 gives an overview of the model runs that are performed.

The cumulus schemes used in the two outer domains were Kain-Fritsch (henceforth KF1) (Kain and Fritsch, 1990) and Kain-Fritsch 2 (henceforth KF2, Kain, 2002). Kain (2002) modified the KF1 scheme, including an additional parametrization for shallow convection and a lowering of the minimum cloud-depth threshold during winter conditions.
Table 1. Overview of the model runs.

\begin{tabular}{ccccc}
\hline Run & Model & Microphysics & Convection & SST $\left({ }^{\circ} \mathrm{C}\right)$ \\
\hline 1a & MM5 & Simple Ice & KF1 & Default \\
2a (ref) & MM5 & Simple Ice & KF2 & Default \\
3a & MM5 & Reisner-Graupel & KF2 & Default \\
1b & WRF & WSM3 & KF1 & Default \\
2b (ref) & WRF & WSM3 & KF2 & Default \\
3b & WRF & Thompson & KF2 & Default \\
SSTP4a & MM5 & Simple Ice & KF2 & Default+4 \\
SSTP10a & MM5 & Simple Ice & KF2 & Default+10 \\
SSTP4b & WRF & WSM3 & KF2 & Default+4 \\
SSTP10b & WRF & WSM3 & KF2 & Default+10 \\
\hline
\end{tabular}

The latter is especially important for forecasting LES, where cloud depth can be $<3 \mathrm{~km}$, as this value was defined as the threshold for convection in KF1.

The selected explicit moisture schemes cover simplified treatment of ice and snow, known as Simple Ice in MM5 (Dudhia, 1989) and WSM3 in WRF (Skamarock, 2008) on one hand. On the other hand more sophisticated schemes have been selected, i.e. Reisner-Graupel or Reisner-2 (Reisner et al., 1998) in MM5, the Thompson scheme (Thompson, 2004) in WRF. The simplified treatment of ice and snow in MM5 and WRF explicitly calculates the amount of cloud water/ice, water vapor, rain and snow. However, it does not include mixed phase microphysics. The sophisticated microphysics schemes account for more microphysical processes and also cover the graupel phase, which is important for the current case study.

\section{Results}

Initially MM5 and WRF utilized the simple explicit moisture schemes and the KF2 cumulus scheme. MM5 and WRF performed well simulating LES within the area and timeframe it was actually observed. First, we verify the model output with the criteria by Niziol (1987):

- $T_{\text {lake }}-T_{850 \mathrm{hPa}}>13^{\circ} \mathrm{C}$. The model temperature difference between the lake and the air at $850 \mathrm{hPa}$ was about $12^{\circ} \mathrm{C}$.

- Wind direction between $230^{\circ}$ and $340^{\circ}$ at a height between the inversion and $850 \mathrm{hPa}$. The modeled wind direction at the surface was southwest, as observed at the Buffalo weather station. This means the air traveled over a large part of Lake Erie.

- Directional shear to $700 \mathrm{hPa}<30^{\circ}$. The directional shear in the ABL was less than $5^{\circ}$.

Despite the correct thermodynamic representation, the forecasted cumulative precipitation was significantly less than 


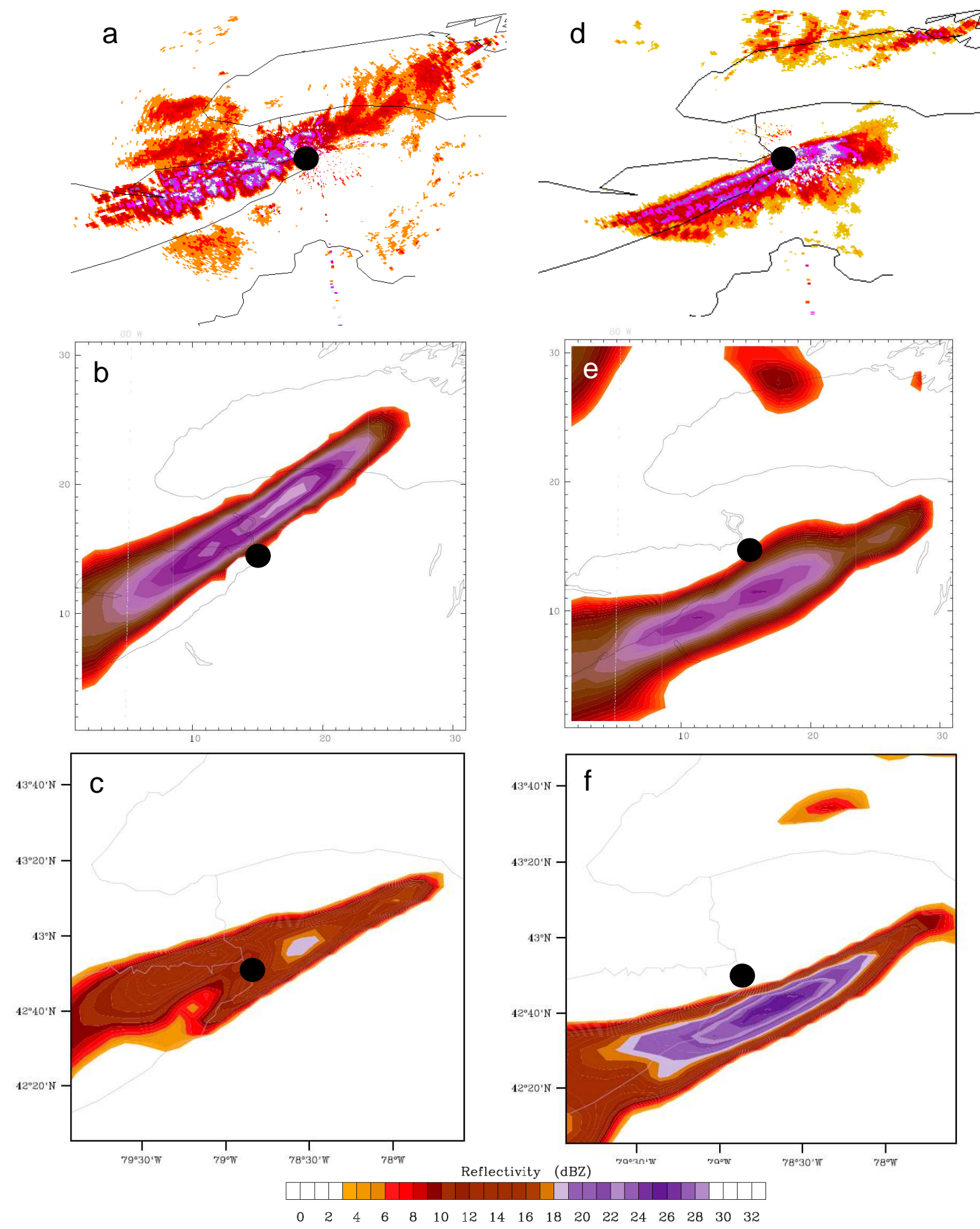

Figure 4. Radar images (domain 2, 9 km resolution) from (a, d) observations in Buffalo, (b, e) MM5, (c, f) WRF for 24 December 2001 , 12:00 UTC (a-c) and 25 December 2001, 06:00 UTC (d-f). The black dot indicates Buffalo.

recorded. The observations indicated a maximum precipitation of $42.3 \mathrm{~mm}$ in $24 \mathrm{~h}$, while MM5 and WRF forecast a maximum precipitation of $18 \mathrm{~mm}$, and $13 \mathrm{~mm}$ respectively. Figure 4 compares radar observations with MM5 and WRF output. The modeled snowbelt is less intense with both mod- els than in reality. Another substantial difference between the observations and the model output is the location of the snowbelt. Both models forecast the snow band more to the south than was observed for 25 December. Especially WRF gives snow mostly far south of Buffalo. 

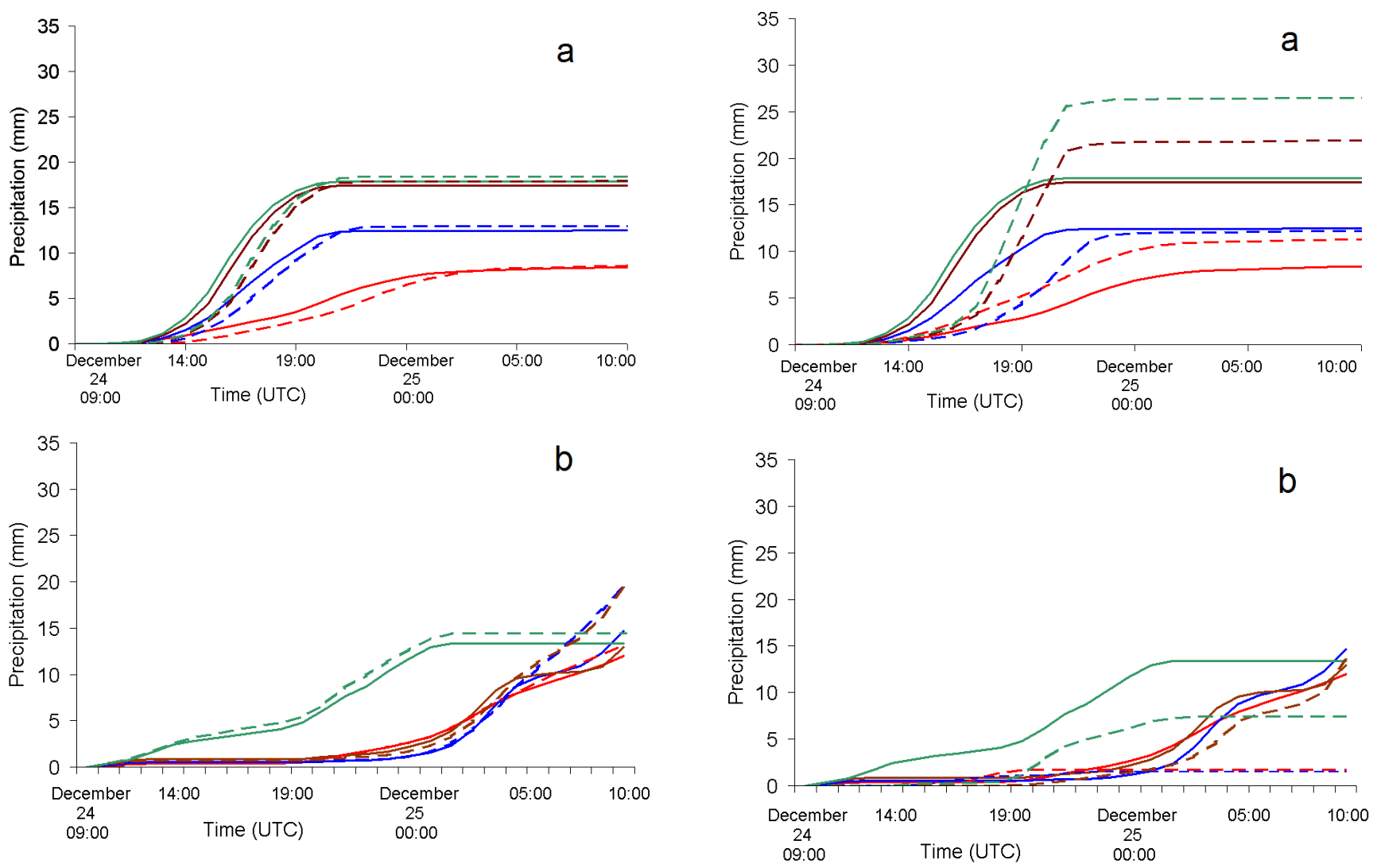

Figure 5. Modeled cumulative precipitation using KF2 (solid lines) and KF1 (dashed lines) and the difference in domains in (a) MM5 and (b) WRF. Domain 1: red, domain 2: blue, domain 3: brown, domain 4: green.

The reference runs show a number of model deficiencies in the model output for LES. In order to explore the possibilities to improve the model skill, we perform a number of sensitivity studies on the most relevant physics for the LES phenomenon, i.e. the convection and mircrophysics schemes, and on the lake temperature.

\subsection{Sensitivity study 1: Kain-Fritsch}

In order to examine whether the updates Kain (2002) made to the cumulus scheme were beneficial in this case, additional runs with MM5 and WRF have been performed with the original Kain-Fritsch cumulus scheme (KF1). In KF2 the minimum cloud-depth to generate convective precipitation is $2 \mathrm{~km}$ for winter conditions. These winter conditions arise when the lifted condensation level (LCL) is colder than $0{ }^{\circ} \mathrm{C}$. The cloud-depth threshold follows

$D_{\text {min }}=\left[\begin{array}{l}4000, T_{\mathrm{LCL}}>20^{\circ} \mathrm{C} \\ 2000, T_{\mathrm{LCL}}<0^{\circ} \mathrm{C} \\ 2000+100 \cdot T_{\mathrm{LCL}}, 0 \leq T_{\mathrm{LCL}} \leq 20^{\circ} \mathrm{C}\end{array}\right](\mathrm{m})$,

where $D_{\min }$ is the cloud-depth threshold for convection, and $T_{\mathrm{LCL}}$ is the temperature at the LCL $\left({ }^{\circ} \mathrm{C}\right)$. In $\mathrm{KF} 1$, the mini-

Figure 6. Modeled cumulative precipitation between (a) the simple ice (solid lines) and Reisner-Graupel (dashed lines) in MM5 and (b) WSM3 (solid lines) and Thompson (dashed lines) explicit moisture schemes in WRF and the difference in domains. Domain 1: red, domain 2: blue, domain 3: brown, and domain 4: green.

mum cloud-depth threshold was set to $3 \mathrm{~km}$ under cold and warm conditions. Figure 5 shows the difference in precipitation between KF1 and KF2. The difference in cumulative precipitation between the four domains will be explained in Sect. 4.2. The only substantial dissimilarity is that KF2 triggers lake effect precipitation earlier and more intensively in MM5 than KF1. This is especially visible in the smallest domains, where the precipitation band is better represented. On the other hand, WRF does not show considerable differences between KF1 and KF2. The total precipitation generated by this event does not differ significantly from the reference runs either. Since LES was triggered slightly earlier using KF2 this one will be used in the following runs.

\subsection{Sensitivity study 2: explicit moisture scheme}

In the following experiment the sophisticated explicit moisture schemes (Reisner-Graupel for MM5 and Thompson for WRF) are utilized and the results are compared to their simplified counterparts. Looking in the second domain in the MM5 runs (Fig. 6a), only minor differences occur in 

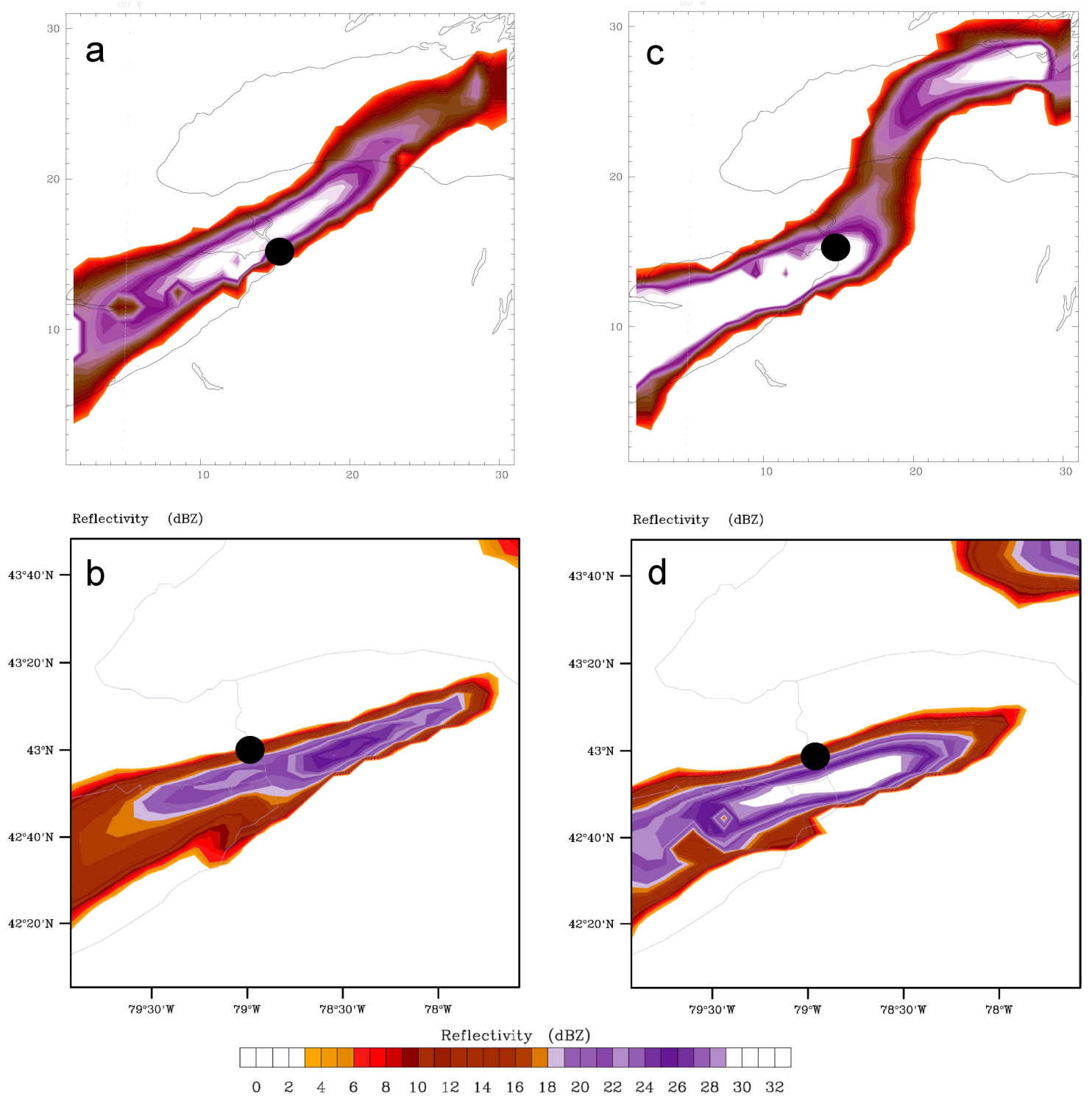

Figure 7. Radar images (domain 2, 9 km resolution) simulated by MM5 (a and c) and WRF (b and d) on 24 December 2001, 12:00 UTC with a Lake Erie temperature $+4 \mathrm{~K}(\mathrm{a}$ and $\mathrm{b})$ and $+10 \mathrm{~K}$ (c and $\mathrm{d})$.

cumulative precipitation between the two simulated lake effect snow belts. Furthermore, the only difference between the moisture schemes in domain 2 seems Reisner-Graupel has a delay in the intensity of the snowbelt (Fig. 6).

In addition, a difference in the forecasted precipitation is noticeable between each domain. A simple explanation exists for the increase of the precipitation in the inner domains: the lake effect snowbelt is very narrow, about $30 \mathrm{~km}$ in width, sometimes smaller. In the outer domain one grid cell is 27 by $27 \mathrm{~km}$, and then the precipitation of the snow band is averaged over a few grid cells in width. In the inner two domains the resolution is finer and therefore the maximum is well defined and therefore higher. Using the simple ice microphysics scheme, domains 3 and 4 seem to have similar results, and as such it appears that domain 4 does not give any extra information, and a grid size of $3 \mathrm{~km}$ is sufficient, at least for this case. On the contrary, using Reisner-Graupel the fourth domain does provide additional information, which could be explained by a smaller width of the snowbelt. However, the spatial characteristics (width and intensity) of the snowbelt seem to be similar for runs with the simple ice and the Reisner-Graupel scheme.

The sensitivity of the WRF results to the selected microphysics schemes is different than in MM5. For all domains the simplified representation of ice and snow (WSM3) gives a better representation of the LES event than with Thompson (Fig. 6b). When the Thompson explicit moisture scheme is used, the precipitation is triggered approximately $4 \mathrm{~h}$ later 
than with WSM3. The total amount of precipitation with the Thompson scheme is considerably less than with WSM3, and smaller than observed as well. Due to these results, the WSM3 microphysics scheme was used in the following WRF runs.

\subsection{Sensitivity study 3 : lake temperature}

The reference run underestimated the cumulative precipitation because the model water temperature of Lake Erie was $4 \mathrm{~K}$ colder than actually observed. In the models, the default sea and lake surface temperature originate from ECMWF climatology, which amounts $\sim 2{ }^{\circ} \mathrm{C}$ for Lake Erie near Buffalo. According to observations by the National Oceanic and Atmospheric Administration, the temperature of northeast Lake Erie on 24 December 2001 was $\sim 6^{\circ} \mathrm{C},\left(43^{\circ} \mathrm{F}\right)$. To examine the model sensitivity to SST, SST was increased by $4 \mathrm{~K}$ to match the observations (referred to as SSTP4).

As an alternative experiment, the temperature of Lake Erie was increased by another $6 \mathrm{~K}$ (SSTP10), since the lake temperature is $\sim 12^{\circ} \mathrm{C}$ at the start of the LES season (Fig. 1). The simulated radar reflectivity for these runs (Fig. 7) show substantial differences from the control runs (Fig. 4). The MM5 run for SSTP4 seems to correspond best with the observations. The $24 \mathrm{~h}$ modeled cumulative precipitation around Buffalo amounts $34.6 \mathrm{~mm}$; a difference with the observations of only $\sim 8 \mathrm{~mm}$. WRF again produces less cumulative precipitation, with only $27.2 \mathrm{~mm}$ (was $\sim 13 \mathrm{~mm}$ in the reference run). When Lake Erie is $\sim 12^{\circ} \mathrm{C}$ the snowbelt is substantially larger with increased precipitation in both runs. The maximum precipitation of the MM5 run amounts $100.4 \mathrm{~mm}$, which is more than twice the observed precipitation. In the previously discussed runs the precipitation was only generated by the explicit moisture scheme. In that case the cumulus scheme transports moisture, but all the generated precipitation was actually generated as explicit precipitation. However, in the SSTP10 run, the atmospheric instability increased significantly due to the warm lake. This instability was sufficiently large to trigger the cumulus scheme to generate precipitation, which added $\sim 11 \mathrm{~mm}$ of precipitation in MM5. In WRF this was not the case, and all precipitation is resolved explicitly, and therefore the maximum $24 \mathrm{~h}$ precipitation was "only" $62.9 \mathrm{~mm}$.

In order to clarify the different model behavior between SSTP4 and the reference on one side and SSTP10 on the other side, it appears that in the reference and SSTP4 run an inversion is evidently present at about $750 \mathrm{hPa}$. This is characteristic for an arctic air mass in which the clouds and precipitation are trapped. The warm lake surface temperature generates convection and vertical motion, bringing moisture upwards. This generates a belt of precipitation over the lake and onto the land. In the MM5 run with SSTP10, the amount of energy released is sufficient to erode the inversion. Consequently, the amount of moisture transported and associated precipitation is substantially higher. In the WRF run with
SSTP10 the amount of energy released is lower and the inversion stays intact. As a result, the precipitation in the WRF run is much lower then in the MM5 run. A point of debate would be if the run with the actual Lake Erie temperature of $6^{\circ} \mathrm{C}$ using the complex moisture scheme would have results that are closer to the observations.

\section{Conclusions}

This paper evaluates the performance of the mesoscale models MM5 and WRF for lake effect snow over Lake Erie and Buffalo on 24 December 2001. In addition, a sensitivity study has been performed by altering the SST, the convection scheme and the microphysics.

The reference runs substantially underestimate the precipitation (using WRF in particular), as a result of underestimated SST used as boundary condition. Increasing the temperature of Lake Erie from $2{ }^{\circ} \mathrm{C}$ to $6^{\circ} \mathrm{C}$ (i.e. the observed value) increases the maximum precipitation with $12-14 \mathrm{~mm}$, and then MM5 simulates the maximum 24-h precipitation with a bias of $\sim 18 \%$, and as such performs rather well. Increasing SST by $10 \mathrm{~K}$ results in another $36 \mathrm{~mm}$ (in WRF) to $66 \mathrm{~mm}$ (in MM5) additional precipitation.

A sensitivity study revealed that in this case the modifications by Kain (2002) in the updated cumulus scheme KainFritsch do not have a significant improvement on the representation of lake effect snow, although these were especially designed for this type of weather phenomenon.

In MM5 the main difference between the simple and the complex microphysics schemes is the sensitivity of precipitation to the resolution of the domains. Reisner-Graupel is more sensitive to a difference between a gridcell size of 3 and $1 \mathrm{~km}$. In WRF the largest difference between WSM3 and Thompson is seen in the timing of the precipitation.

Acknowledgements. This study was supported by a grant from the Wageningen University Foundation. In addition, we thank Ingeborg Zuurendonk and one additional reviewer for their valuable comments on an earlier version of the manuscript.

Edited by: F. Stel

Reviewed by: I. Zuurendonk and another anonymous referee 


\section{References}

Ballentine, R. J., Stamm, A. J., Chermack, E. E., Byrd, G. P., and Schleede, D.: Mesoscale model simulation of the 4-5 January 1995 lake-effect snowstorm, Weather Forecast., 13, 893-919, 1998.

Dudhia, J.: Numerical study of convection observed during the Winter Monsoon Experiment using a mesoscale two-dimensional model, J. Atmos. Sci., 46, 3077-3107, 1989.

Grell, G. A., Dudhia, J., and Stauffer, D. R.: A description of the fifth generation Penn State/NCAR mesoscale model (MM5), NCAR Technical Note, NCAR/TN-398+STR, 117, 1994.

Holtslag, A. A. M. and Boville, B. A.: Local versus nonlocal boundary-layer diffusion in a global climate model, J. Climate, 6, 1825-1842, 1993.

Hong, S.-Y. and Pan, H.-L.: Nonlocal boundary layer vertical diffusion in a medium-range forecast model, Mon Wea. Rev., 124, 2322-2339, 1996.

Holroyd, E. W.: Lake-effect cloud bands as seen from weather satellites, J. Atmos. Sci., 28, 1165-1170, 1971.

Kain, J. S.: The Kain-Fritsch convective parameterization: an update, J. Appl. Meteor., 43, 170-181, 2002.

Kain, J. S. and Fritsch, J. M.: A one-dimensional entraining/detraining plume model and its application in convective parameterization, J. Atmos. Sci., 47, 2784-2802, 1990.

Lavoie, R. L.: A mesoscale numerical model of lake-effect storms, J. Atmos. Sci., 29, 1025-1040, 1972.

Maesaka, T., Moore, G. W. K., Liu, Q., and Tsuboki, K.: A simulation of a lake effect snow-storm with a cloud resolving numerical model, Geophys. Res. Lett., 33, L20813, doi:10.1029/2006GL026638, 2006.
Niziol, T. A.: Operational forecasting of lake-effect snowfall in western and central New York, Weather Forecast., 2, 310-321, 1987.

Niziol, T. A., Snyder, W. R., and Waldstreicher, J. S.: Winter weather forecasting throughout the eastern United States. Part IV: Lake effect snow, Weather Forecast., 10, 61-77, 1995.

Reisner, J. and Rasmussen, J.: Explicit forecasting of supercooled liquid water in winter storms using the MM5 meso-scale model, Q. J. Roy. Meteor. Soc., 124B, 1071-1107, 1998.

Scott, C. P. J. and Sousounis, P. J.: The utility of additional soundings for forecasting lake-effect snow in the Great Lakes region, Weather Forecast., 16, 448-462, 2001.

Skamarock, W. C., Klemp, J. B., Dudhia, J., Gill, D. O., Barker, D. M., Duda, M., Huang, X.-Y., Wang, W., and Powers, J. G.: A Description of the Advanced Research WRF Version 3, NCAR Technical Note, 2008.

Steenburgh, W. J. and Onton, D. J.: Multiscale analysis of the 7 December 1998 Great Salt Lake-effect snowstorm, Mon. Wea. Rev., 129, 1296-1317, 2001.

Thompson, G., Rasmussen, R. M., and Manning, K.: Explicit Forecasts of Winter Precipitation Using an Improved Bulk Microphysics Scheme. Part I: Description and Sensitivity Analysis, Mon. Wea. Rev., 132, 519-542, 2004.

Wilson, J. D.: Effect of Lake Ontario on precipitation, Mon. Wea. Rev., 105, 207-214, 1977. 